\title{
Expression of cyclins and cyclin dependent kinases in human benign and malignant melanocytic lesions*
}

\author{
J Georgieva, P Sinha, D Schadendorf
}

Klinische

Kooperationseinheit für Dermatoonkologie (DKFZ),

Universitätsklinikum

Mannheim,

Universität

Heidelberg, Theodor

Kutzer Ufer 1, D-68135

Mannheim, Germany

J Georgieva

D Schadendorf

Institut für

Laboratorium medizin und Pathobiochemie, Universtitätsklinikum Charité, Humboldt Universität zu Berlin, D-10117, Berlin,

Germany

P Sinha

Correspondence to:

Dr Schadendorf

d.schadendorf@

dkfz-heidelberg.de

Accepted for publication 10 April 2000

$\star$ Dedicated to Professor E Köttgen on his 60th birthday

\begin{abstract}
Aims-The regulation of cell proliferation is a key event in normal development, pathophysiological responses to injury, and tumorigenesis. The orderly progression of cells through the cell cycle depends on a finely tuned balance between the concentrations of activated cyclins and cyclin dependent kinases. This study was undertaken to compare the expression of cell cycle regulators in benign and malignant melanocytic lesions during tumour progression.
\end{abstract}

Methods-Immunohistochemistry was used to analyse 49 primary cutaneous malignant melanomas, 18 metastatic melanomas, and 12 histologically confirmed naevus cell naevi for their expression of cyclins (A, B1, D1, D2, D3, and E) and cyclin dependent kinases (CDK1, CDK2, and CDK4).

Results-Cyclin E and CDK2 had the highest expression patterns in human cutaneous melanomas and metastases and correlated positively with histological type and tumour stage. Cyclins B1, D2, and D3

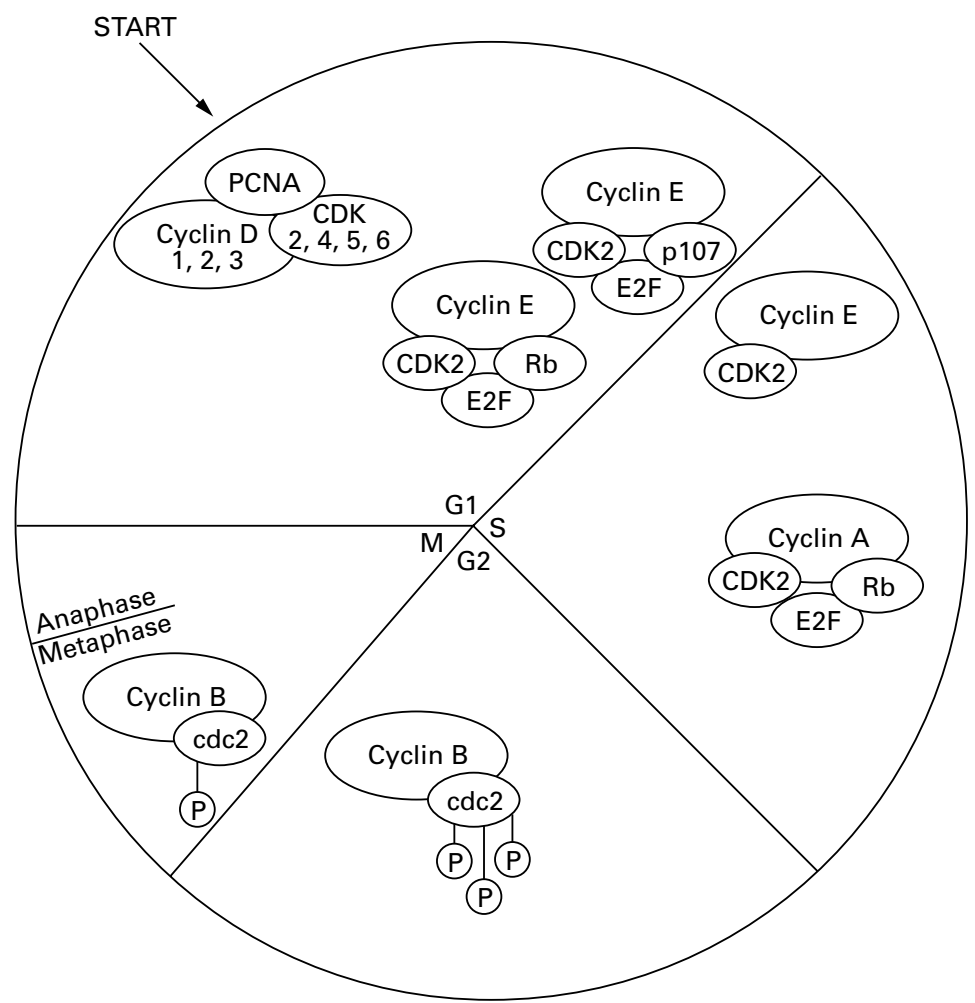

Figure 1 Simplified scheme of the different phases of the cell cycle and their components. Not shown in the scheme are the inhibitors of the cyclin-CDK complexes $(p 15, p 16, p 18$, p21, and p27) and other cyclin activating kinases and phosphatases. had significantly increased expression in metastases, but normal or even decreased expression in primary melanomas. However, cyclins $A$ and D1, and CDK1 and CDK4 were expressed very weakly in situ with no significant differences between naevi, melanomas, or metastases, and there was no correlation with histopathological staging. The specificity of recognition by the antibodies used was confirmed by western blotting on a panel of seven human melanoma cell lines. Cyclins A, B, and $E$ were expressed by all seven, whereas cyclin D1 was detectable in six of seven and CDK 2 and cdc 2 were present in five of seven lines analysed.

Conclusions-Taken together, this study demonstrated a significant increase of cyclin $E$ and CDK2 expression during tumour progression in malignant melanomas.

(f Clin Pathol 2001;54:229-235)

Keywords: melanoma; immunohistology; naevus; cyclin $\mathrm{E}$; cyclin dependent kinase 2; cyclin B1

Cell cycle regulation depends on a finely tuned balance between the concentrations of activated cyclins and cyclin dependent kinases (CDKs) that provide positive growth signals, and kinase inhibitors that suppress these effects. $^{1-4}$ In their catalytically active state, cyclin-CDK complexes enable the cell to traverse specific phases of the cell division cycle: the preparatory or check point phases (G1 and G2), DNA synthesis (S), and mitosis (M). Five major classes of mammalian cyclins that are synthesised and degraded at specific points during the cell cycle $^{1}$ have been described so far (cyclins A-E). Each cyclin has a unique pattern of expression; and its timing is key in determining at which phase the associated CDK is active (fig 1 ). Consequently, cyclin abundance is rate limiting for progression through the different stages of the cell cycle. G1 cyclins (cyclins D1, D2, D3, and E) facilitate movement through the earliest phases and across the G1/S boundary. ${ }^{56}$ D-type cyclins are synthesised in early G1 and bind to and activate $\mathrm{CDK} 4$ and $\mathrm{CDK} 6$ as cells leave the quiescent phase. They regulate the function of the tumour suppressor protein $\mathrm{Rb}$, which can arrest the cell cycle in G1 in its hypophosphorylated form (the functionally active form) and relieve this inhibition in its phosphorylated form. ${ }^{7}$ Cyclin E is thought to act at the G1/S transition itself and to push cells through a crucial checkpoint and thereby drive cell division. ${ }^{8}$ Cyclin A appears later in the cell 
Table 1 Subtypes, thickness classes, levels, sex, and age distributions and localisation of 79 melanocytic tumours (49 primary tumours, 18 metastases, 12 nevi) used in this study

\begin{tabular}{lc}
\hline Parameter & No. of tumours \\
\hline Primary cutaneous melanoma subtypes & \\
SSM & 25 \\
NMM & 7 \\
LMM & 11 \\
UCM & 6 \\
Melanoma metastases & \\
Lymph node & 4 \\
Skin/subcutis & 8 \\
Unknown origin & 6 \\
Naevus cell naevi subtypes & \\
Compound & 4 \\
Dermal & 4 \\
Junctional & 4 \\
Tumour thickness & 24 \\
<1.5 mm & 25 \\
>1.5 mm & \\
Level of invasion (Clark) & 8 \\
II & 11 \\
III & 21 \\
IV + V & 9 \\
Unknown & \\
Sex distribution of all specimens & 42 \\
Male & 37 \\
Female & \\
\hline
\end{tabular}

LMM, lentigo maligna melanoma; NMM, nodular malignant melanoma; SSM, superficial spreading melanoma; UCM, unclassified melanoma.

cycle and, together with CDK2, regulates progression through the $\mathrm{S}$-phase ${ }^{9}$; cyclin $\mathrm{B} 1$ is active during $\mathrm{G} 2$ and mitosis when it forms a kinase complex with CDK1.

In view of their key role in regulation of the cell cycle, the cyclins are possible targets for oncogenic abnormalities. ${ }^{10}$ Altering any of the different components that activate or inhibit the cell cycle can induce an imbalance through which the cells might acquire a growth advantage. Consequently, cyclins may play an important role in tumour development and progression, and their periodic appearance in distinct phases of the cell cycle suggests that they could be used as prognostic markers. ${ }^{11}$ Based on investigations that show an over abundance of cyclins in different tumour types, we hypothesised that cyclins might be involved in tumorigenesis and might correlate with tumour progression in melanoma. Immunohistochemical staining was performed on tissues from naevi, primary melanomas, and metastases to explore the expression of cyclins and their kinase partners. Specificity was confirmed by western blot analysis on human melanoma cell lines.

\section{Materials and methods}

PATIENTS AND SAMPLES

Surgical tissues from 79 patients treated from 1991-6 at the Virchow Hospital, Berlin, were used. The samples included 49 primary cutaneous melanomas, 18 melanoma metastases, and 12 histologically confirmed naevi (table 1). For statistical reasons, primary cutaneous melanomas were divided into different groups according to Clark level and Breslow thickness: 24 tumours had a tumour thickness $<1.5 \mathrm{~mm}$ and $25>1.5 \mathrm{~mm}$; eight melanomas were histologically evaluated at Clark level II, 11 at level III, and 21 at level IV+V.

ANTIBODIES AND IMMUNOHISTOCHEMISTRY

Surgical samples were immersed immediately in liquid nitrogen, embedded in Cryomatrix and kept at $-80^{\circ} \mathrm{C}$. Cryostat sections $(4-5 \mu \mathrm{m})$ were prepared at $-25^{\circ} \mathrm{C}$, placed on poly-Llysine coated slides, dried for 20 minutes, fixed with ice cold acetone, and used immediately or stored at $-20^{\circ} \mathrm{C}$. Immunohistological staining was done as described using a standard alkaline phosphatase antialkaline phosphatase (APAAP) technique. ${ }^{12}$ Mouse monoclonal and rabbit polyclonal antibodies raised against recombinant human cyclins A, B1, D1, D2, $\mathrm{D} 3$, and $\mathrm{E}$, and $\mathrm{CDK} 1, \mathrm{CDK} 2$, and CDK4 were titrated against the tumour sections. Table 2 lists their sources, dilutions, and isotypes. The specificity of antibody reactivity was demonstrated by western blotting (see below).

\section{SEMIQUANTITIVE ASSESSMENT OF STAINING}

All slides were evaluated by two investigators (JG and DS) using a standard evaluation form as described previously. ${ }^{12}$ The proportion of positive cells was scored according to five categories $(-, 0-5 \% ;+, 5-25 \%$; ++, 26-50\%; +++, 51-75\%; ++++, 75-100\%). Discrepancies in the interpretation were resolved by a second parallel reading of the slides. Interobserver difference was found to be $9.3 \%$.

\section{STATISTICAL ANALYSIS}

The significance of the differences between the four groups (naevi, primary melanomas $<1.5 \mathrm{~mm}$, primary melanomas $>1.5 \mathrm{~mm}$, and metastases) was determined by the $\chi^{2}$ test, the Mann-Whitney U Wilcoxon-Rang sum test, and the Kruskall-Wallis test and controlled by the Bonferroni method. Significance was set at $\mathrm{p}<0.02$. Differences between the Clark levels II, III, and IV+V were significant at $\mathrm{p}<0.03$.

\section{CELL CULTURE}

Melanoma cells were maintained as described previously. ${ }^{12}$ The following human melanoma cell lines were used: SK-Mel-23, WM 98-1, UKRV-Mel-4, SK-Mel-37, UKRV-Mel-2, and MV3.

Table 2 Antibodies used for western blotting and immunohistochemistry

\begin{tabular}{llll}
\hline Antibody & Specificity & Isotype & Source \\
\hline Anticyclin A (BF683) & Cyclin p60 & IgG1 & Santa Cruz Biotechnology, Santa Cruz, USA \\
Anticyclin B1 (GNS1) & Human, mouse, rat cyclin B1 p62 & IgG1 & Santa Cruz Biotechnology \\
Anticyclin D1 (HD11) & Human, mouse, cyclin D1 p34 & IgG1 & Santa Cruz Biotechnology \\
Anticyclin D2 & Human cyclin D2 & IgG2a & Pharmingen, San Diego, USA \\
Anticyclin D3 & Human cyclin D3 & IgG1 & Pharmingen \\
Anticyclin E & Human cyclin E & IgG2b & Pharmingen \\
Anti-CDK1 (cdc2p34) & Human, mouse, xenopus CDK1 & IgG2a & Santa Cruz Biotechnology \\
Anti-CDK2 (M 2) & Human, mouse, rat CDK2, p33 & Polyclonal antibody (rabbit) & Santa Cruz Biotechnology \\
Anti-CDK4 (C-22) & Human, mouse, rat CDK4, p34 & Polyclonal antibody (rabbit) & Santa Cruz Biotechnology \\
\hline
\end{tabular}


$60 \mathrm{kDa}$

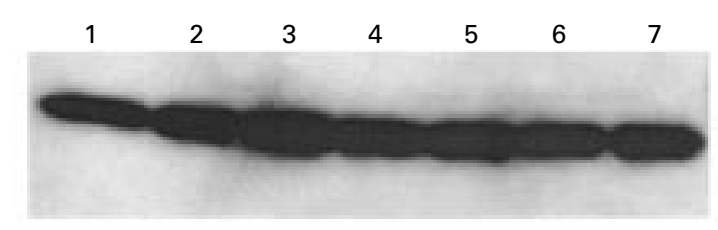

Cyclin A

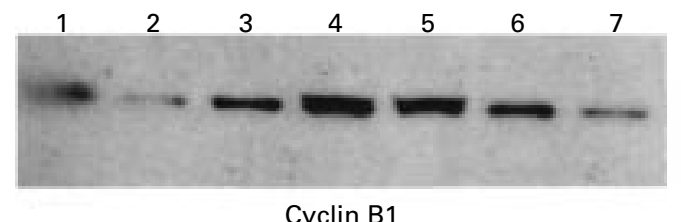

Cyclin B1

$62 \mathrm{kDa}$

$36 \mathrm{kDa}$

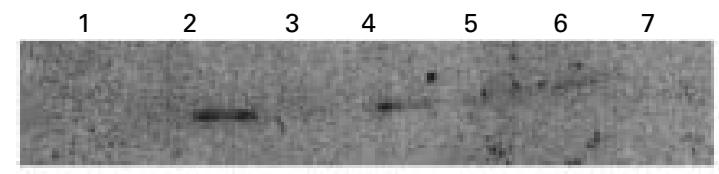

Cyclin D1

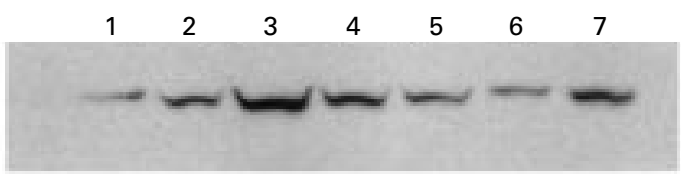

Cyclin E

$50 \mathrm{kDa}$

$34 \mathrm{kDa}$
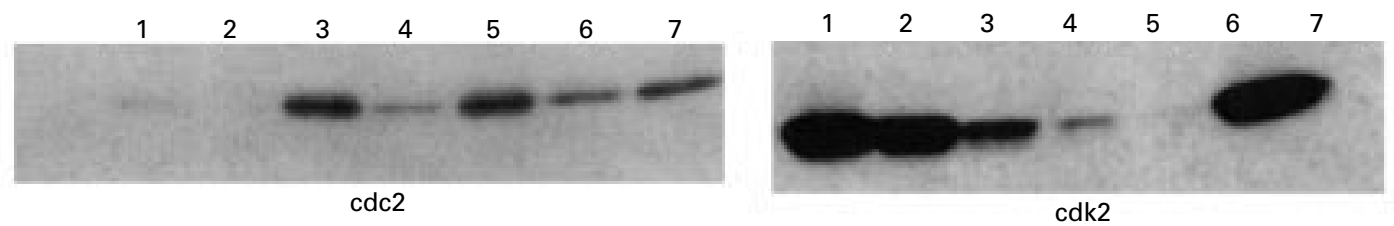

$33 \mathrm{kDa}$

Figure 2 Western blot analysis using monoclonal antibodies listed in table 2. Seven human melanoma lines were analysed: 1, SK-Mel-23;2, WM 98-1; 3, UKRV-Mel 4; 5, SK-Mel-37; 6, UKRV-Mel-2; and 7, MV3.

GEL ELECTROPHORESIS AND WESTERN BLOTTING Monolayer cell cultures were harvested in exponential growth phase and lysed in a solubilisation buffer containing $9 \mathrm{M}$ urea, $4 \%$ CHAPS, $20 \mathrm{mM}$ spermine, and $40 \mathrm{mM}$ DTT (all purchased from Sigma, Deisenhofen, Germany) for 60 minutes at ambient temperature. Subsequently, the lysate was centrifuged at $40000 \times g$ for 60 minutes. Proteins $(10 \mu \mathrm{g} / \mathrm{slot})$ were fractionated using a vertical electrophoresis system (Novex, San Diego, USA). A semi-dry blotting procedure using a discontinuous buffer system and polyvinyldifluoride (PVDF; Millipore, Bedford, USA) was used $\left(10 \mathrm{~V}, 0.8 \mathrm{~mA} / \mathrm{cm}^{2}, 5 \mathrm{~W}\right.$ for 150 minutes). Remaining protein binding sites were blocked by incubation with Blotto (5\% low fat milk powder in $12.5 \mathrm{mM}$ Tris buffer, $50 \mathrm{mM} \mathrm{NaCl}$, 2.5 mM EDTA, pH 7.5; Merck, Darmstadt, Germany). After washing (10 mM Tris, 150 $\mathrm{NaCl}, 0.02 \%$ Tween $20, \mathrm{pH} 7.4$ ), blots were exposed to primary antibodies in Blotto $(1 / 1000$ dilution in washing buffer; $0.1 \mathrm{ng} / \mathrm{ml}$ final) for 60 minutes. After another washing step, the peroxidase labelled secondary antibody in Blotto ( $1 / 1000$ dilution; $0.5 \mu \mathrm{g} / \mathrm{ml}$ final) was added. Subsequently, blots were washed and developed using ECL reagent according to the manufacturer's guidelines (Amersham-Pharmacia, Stockholm, Sweden).

\section{Results}

WESTERN BLOTTING ON MELANOMA CELL LINES Western blots on seven human melanoma cell lines were performed to demonstrate the specificity of the antibody reactivity. Cyclin A was strongly expressed in all seven cell lines (fig 2). Similarly, anticyclin B1 (fig 2) and anticyclin E (fig 2) antibodies detected appropriate bands of $60 \mathrm{kDa}$ and $45 \mathrm{kDa}$, respectively, in all cell lines tested. Cyclin D1 (three reactive; fig 2), cdc2 (six reactive; fig 2), and CDK2 (five reactive; fig 2) were detected in varying quantities in the seven melanoma lines.

IMMUNOHISTOCHEMISTRY ON TISSUE SECTIONS Staining was performed on a set of benign, low risk $(<1.5 \mathrm{~mm})$, intermediate to high risk primary melanomas $(>1.5 \mathrm{~mm}$ ), and metastases to detect factors associated with tumour progression and prognosis. Four cyclins as well as CDK2 and cdc2 were analysed.

No crossreacting bands were detected in any of the gels analysed.

\section{Cyclins}

Cyclins A and D1 were expressed weakly in all melanocytic lesions. More than two thirds of all sections were not reactive (table 3). Cyclin B1 (fig 3A) was also weakly expressed in most lesions, and expression increased with tumour thickness. Significant differences in cyclin B1 staining were noted between low risk melanomas and metastases $(p=0.01)$ and between tumour subtypes (superficial spreading melanoma (SSM) $v$ nodular malignant melanoma (NMM), $p=0.02)$. Ninety per cent of all primary melanomas showed almost no expression (0-5\%) of cyclin D2. Anticyclin D3 (fig 3B) showed a reaction similar to that of anticyclin D2; however, a significant difference was found between metastases and low risk primary melanomas $(\mathrm{p}=0.002)$, as well as 

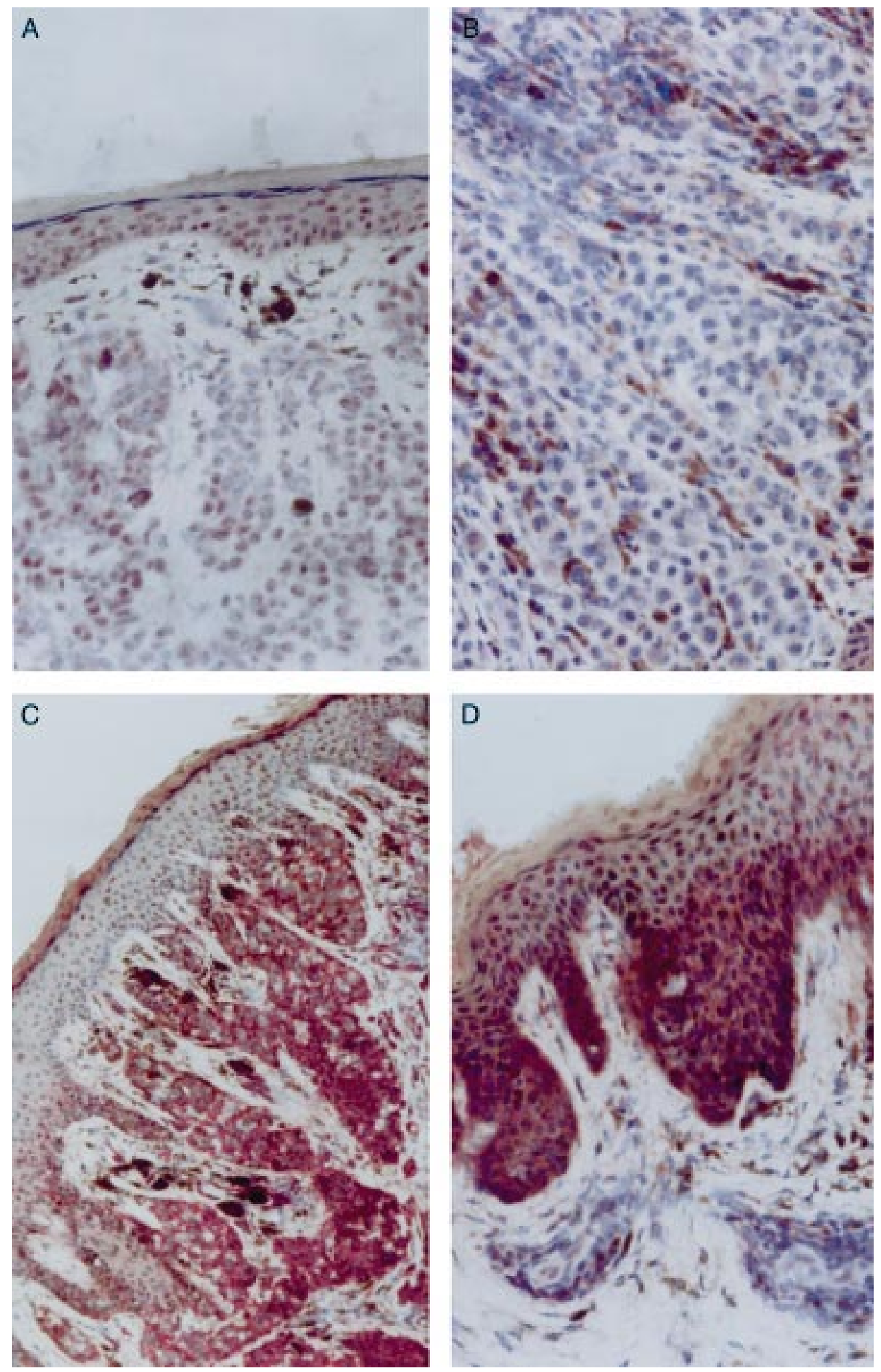

Figure 3 Immunohistological staining of tissue sections using the alkaline phosphatase antialkaline phosphatase

(APAAP) technique. (A) A primary melanoma stained with an anticyclin B1 antibody (magnification, $\times 20$ ) and (B) a metastasis stained with anticyclin D3 (magnification, $\times 80)$. (C) Immunohistological staining of a primary melanoma with an anticyclin $E$ (magnification, $\times 20$ ) and $(D)$ with an anti-CDK2 monoclonal antibody (magnification, $\times 40$ )

between intermediate and high risk primary melanomas ( $\mathrm{p}=0.002$ (table 3). Anticyclin E (fig $3 \mathrm{C}$ ) demonstrated the strongest staining of tumour tissue in our study. Fourteen of 16 metastases, nine of 21 intermediate to high risk primaries, and none of the low risk primary melanomas strongly expressed (75-100\%) cyclin E (table 3). These results were parallelled by the significant differences between metastases and naevi $(p=0.01)$, low risk primary melanomas $(p=0.0001)$, and intermediate to high risk primary melanomas 
Table 3 Number of positively stained tissue sections in each category divided into melanocytic naevi, low risk primary $(<1.5 \mathrm{~mm})$, intermediate to high risk primary melanomas $(>1.5 \mathrm{~mm})$, and metastases

\begin{tabular}{|c|c|c|c|c|c|c|}
\hline & & $0-5 \%$ & $6-25 \%$ & $26-50 \%$ & $51-75 \%$ & $76-100 \%$ \\
\hline \multirow[t]{4}{*}{ Cyclin A } & Naevi & 9 & 3 & 0 & 0 & 0 \\
\hline & $<1.5 \mathrm{~mm}$ & 18 & 4 & 0 & 0 & 0 \\
\hline & $>1.5 \mathrm{~mm}$ & 15 & 7 & 1 & 0 & 0 \\
\hline & Metastases & 15 & 3 & 0 & 0 & 0 \\
\hline \multirow[t]{4}{*}{ Cyclin B1 } & Naevi & 5 & 3 & 4 & 0 & 0 \\
\hline & $<1.5 \mathrm{~mm}$ & 13 & 6 & 3 & 0 & 0 \\
\hline & $>1.5 \mathrm{~mm}$ & 12 & 7 & 4 & 0 & 0 \\
\hline & Metastases & 5 & 0 & 7 & 2 & 2 \\
\hline \multirow[t]{4}{*}{ Cyclin D1 } & Naevi & 4 & 7 & 1 & 0 & 0 \\
\hline & $<1.5 \mathrm{~mm}$ & 13 & 7 & 2 & 0 & 0 \\
\hline & $>1.5 \mathrm{~mm}$ & 6 & 12 & 5 & 0 & 0 \\
\hline & Metastases & 10 & 4 & 1 & 0 & 0 \\
\hline \multirow[t]{4}{*}{ Cyclin D2 } & Naevi & 5 & 4 & 2 & 1 & 0 \\
\hline & $<1.5 \mathrm{~mm}$ & 19 & 2 & 0 & 0 & 0 \\
\hline & $>1.5 \mathrm{~mm}$ & 19 & 1 & 1 & 0 & 0 \\
\hline & Metastases & 7 & 6 & 0 & 0 & 0 \\
\hline \multirow[t]{4}{*}{ Cyclin D3 } & Naevi & 5 & 2 & 3 & 1 & 0 \\
\hline & $<1.5 \mathrm{~mm}$ & 11 & 6 & 5 & 0 & 0 \\
\hline & $>1.5 \mathrm{~mm}$ & 11 & 6 & 2 & 2 & 0 \\
\hline & Metastases & 3 & 3 & 7 & 3 & 1 \\
\hline \multirow[t]{4}{*}{ Cyclin E } & Naevi & 1 & 3 & 1 & 2 & 5 \\
\hline & $<1.5 \mathrm{~mm}$ & 2 & 15 & 2 & 2 & 0 \\
\hline & $>1.5 \mathrm{~mm}$ & 3 & 3 & 5 & 1 & 9 \\
\hline & Metastases & 0 & 0 & 2 & 0 & 14 \\
\hline \multirow[t]{4}{*}{ CDK1 } & Naevi & 4 & 4 & 3 & 0 & 0 \\
\hline & $<1.5 \mathrm{~mm}$ & 12 & 8 & 1 & 0 & 0 \\
\hline & $>1.5 \mathrm{~mm}$ & 12 & 3 & 4 & 1 & 1 \\
\hline & Metastases & 8 & 4 & 2 & 3 & 0 \\
\hline \multirow[t]{4}{*}{ CDK2 } & Naevi & 4 & 5 & 2 & 0 & 1 \\
\hline & $<1.5 \mathrm{~mm}$ & 0 & 4 & 14 & 3 & 1 \\
\hline & $>1.5 \mathrm{~mm}$ & 3 & 5 & 3 & 3 & 8 \\
\hline & Metastases & 0 & 3 & 2 & 7 & 5 \\
\hline \multirow[t]{4}{*}{ CDK4 } & Naevi & 0 & 3 & 4 & 3 & 1 \\
\hline & $<1.5 \mathrm{~mm}$ & 7 & 3 & 11 & 1 & 0 \\
\hline & $>1.5 \mathrm{~mm}$ & 7 & 5 & 3 & 3 & 2 \\
\hline & Metastases & 7 & 3 & 3 & 2 & 1 \\
\hline
\end{tabular}

$(\mathrm{p}=0.001)$, respectively. Furthermore, a significant association between tumour subtypes and cyclin E expression was found. Strong invasively growing NMM showed higher expression of cyclin E than SSM ( $p=0.0007)$ and slowly growing lentigo maligna melanoma $(\mathrm{LMM}) \quad(\mathrm{p}=0.001)$. In addition, primary melanomas, categorised by Clark level, showed a significant association between tumour invasiveness and cyclin E expression (Clark level II $v$ Clark level IV $+\mathrm{V}, \mathrm{p}=0.02$; Clark level III $v$ $\mathrm{IV}+\mathrm{V}, \mathrm{p}=0.03$ ).

Cyclin dependent kinases

CDK2 (like its partner cyclin E) was increasingly detectable in primary melanomas with tumour penetration and metastases (table 3 ). Naevi showed only weak CDK2 expression; this was significantly lower when compared with melanomas $<1.5 \mathrm{~mm} \quad(\mathrm{p}=0.003)$, melanomas $>1.5 \mathrm{~mm}(\mathrm{p}=0.004)$ (fig $3 \mathrm{D}$ ), and metastases $(p=0.001)$. Metastatic lesions demonstrated the strongest CDK2 staining, followed by intermediate to high risk primary melanomas $(p=0.01)$. In addition, aggressively growing NMM showed an increased expression compared with LMM ( $p=0.004)$ and SSM ( $p=0.009)$. CDK4 was moderately expressed in a uniform manner in all melanocytic lesions without significant differences (table 3). Even weaker expression patterns were seen in lesions stained with CDK1 (table 3). No significant difference could be found.

Correlation of cyclin $\mathrm{E}$ and CDK2

Statistical analysis was done with the Spearman-Rang coefficient to compare the expression of cyclin $\mathrm{E}$ with its $\mathrm{CDK}$ (CDK2) and to verify the observations (fig $4 \mathrm{~A}$ ). The significance level was set at $\mathrm{p}<0.05$. A positive correlation was found between primary melanomas $<1.5 \mathrm{~mm}$ stained with anticyclin $\mathrm{E}$ and anti-CDK2 $(r=0.72, \mathrm{p}=0.001)$. Eight of 17 melanoma sections (four NMM, four SSM) expressed both cyclin E and CDK2 very strongly. Metastases and naevi showed no significant correlation between cyclin $\mathrm{E}$ and CDK2; however, $62 \%$ of the metastases had equal expression patterns for both proteins.

Correlation of cyclin $E$ with other cyclins A significant relation was found between metastases $(r=0.49, \mathrm{p}=0.05)$ and primary melanomas $<1.5 \mathrm{~mm}(r=0.66, \mathrm{p}=0.002)$ stained with anticyclin $\mathrm{E}$ and anticyclin D3 (fig 4B). There was also a correlation between
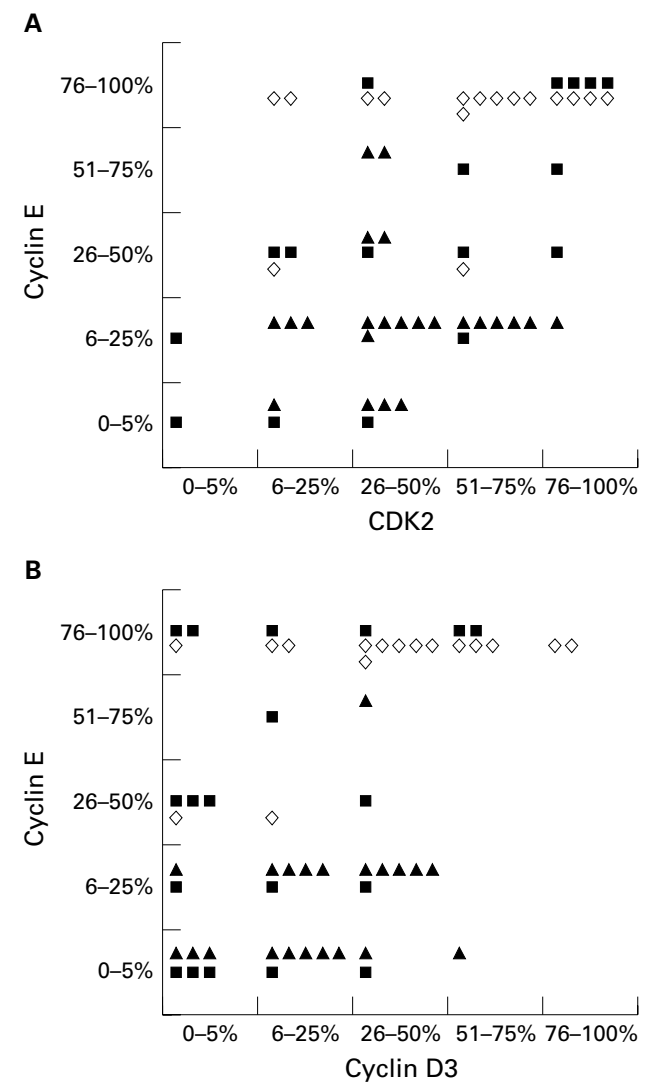

C

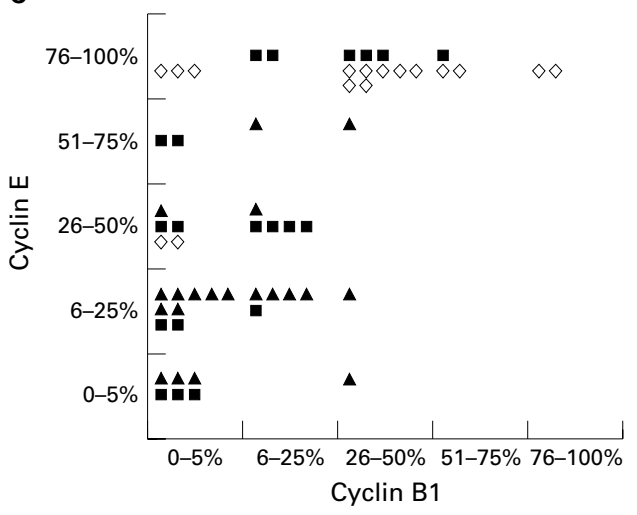

Figure 4 Correlation of cyclin $E$ expression with (A) CDK2, (B) cyclin D3, and (C) cyclin B1. 
cyclin $\mathrm{E}$ and cyclin B1 expression in metastatic melanomas $(r=0.53, \mathrm{p}=0.04)$ and melanomas $<1.5 \mathrm{~mm}(r=0.63, \mathrm{p}=0.004)$ (fig $4 \mathrm{C})$.

\section{Discussion}

Our study shows a significant increase in the expression of cyclin $\mathrm{E}$ and its kinase $\mathrm{CDK} 2$ in metastases compared with naevi and primary melanomas of different thickness. In a recent report by Bales et al increased concentrations of cyclin E were associated with tumour thickness in primary melanomas from a group of 21 patients. ${ }^{13}$ Cyclin E overexpression has been detected previously in breast cancer cell lines ${ }^{14}$ and was shown to be connected with tumour aggressiveness and tumour stage. ${ }^{15}$ Increased function was also found in uterine cancer cell lines ${ }^{16}$ and ovarian carcinomas ${ }^{17}$; however, cyclin $\mathrm{E}$ was not associated with prognosis in ovarian cancer.

Wang et al reported strongly increased expression in colorectal cancers compared with corresponding non-neoplastic mucosa in $97 \%$ of the patients studied and suggested cyclin E as a prognostic marker. ${ }^{18}$ In addition, there was evidence showing increased CDK2 function.

Among the cell cycle regulatory proteins, cyclin D1 appears to be most strongly implicated in tumorigenesis. ${ }^{10}$ It has often been reported to be amplified and overexpressed-for example, in some cases of squamous cell carcinoma, ${ }^{19}$ and in liver, ${ }^{20}$ breast, ${ }^{21}$ and oesophageal cancer. ${ }^{22}$ However, increased function of cyclin D1, with a low or missing amplification rate, has also been detected in several tumours (squamous cell carcinomas, colorectal carcinomas, and bladder tumours).$^{23-25}$ Furthermore, in earlier investigations on breast cancer, uterine tumours, and acute lymphoblastic leukaemia in childhood cyclin D1 was reported to be associated with increased carcinoma stage and pathological grade and to serve as a prognostic factor. ${ }^{26-28}$ Similarly, in some melanoma cell lines ${ }^{29}$ and melanoma metastases, ${ }^{30}$ moderate to high cyclin D1 expression was detected by immunoblotting. In contrast to the above studies, cyclin D1 was only weakly expressed in melanocytic lesions, in accordance with an immunohistochemical study by Inohara et al, who reported cyclin D1 overexpression in one of 10 melanomas. ${ }^{31}$ In contrast to cyclin D1, no reports on cyclin D2 and cyclin D3 expression in malignant melanomas have been published so far and investigations on other tumours differ widely. ${ }^{24}$ 32-34

Cyclin A, one of the first cell cycle proteins assumed to be involved in carcinogenesis, was found to be highly expressed in human haematological malignancies and in breast cancer cell lines. ${ }^{915}$ However, in a colorectal cancer study, reduced expression patterns were detected in $63 \%$ of the cases, which could be considered as a loss of cell cycle control. ${ }^{18}$ In our study, cyclin A was weakly expressed in tissue sections in contrast to the high expression detected by western blotting of cell lines. These results are partly in contrast to a recent report comparing naevi $(\mathrm{n}=2)$ with melanoma metastases $(\mathrm{n}=10)$ by means of western blotting and densitometric analysis. ${ }^{35}$ However, this technique does not allow the discrimination of cells contributing to the "positive signal" and the sample number was low.

Taken together, our investigation demonstrates the raised expression of cyclin $\mathrm{E}$ and CDK2 in human cutaneous melanomas and metastases that becomes more severe, and a positive correlation between cyclin $\mathrm{E}$ and CDK2 expression and histological type and tumour stage. To examine the potential use of cyclin E clinically as a prognostic marker, prospective studies with a larger number of patients are required.

1 Cordon-Cardo C. Mutation of cell-cycle regulators. Biological and clinical implications for human neoplasia [review] Am f Pathol 1995; 147:545-60.

2 Wang Y, Becker D. Differential expression of the cyclindependent kinase inhibitors p16 and p21 in the human melanocytic system. Oncogene 1996;12:1069-75.

3 Hunter T, Pines J. Cyclins and cancer II: cyclin D and cdk inhibitors come of age. Cell 1994;79:573-82.

$4 \mathrm{Kamb}$ A. Cell-cycle regulators and cancer. Trends Genet 1995;11:136-40.

5 Reed SI. G1 specific cyclins: in search of an S-phase promoting factor. Trends Genet 1991;7:95-9.

6 Sherr CJ. Mammalian G1 cyclins. Cell 1993;73:1059-65.

7 Hinds PW, Weinberg RA. Tumour suppressor genes. Curr Opin Genet Dev 1994;4:135-41.

8 Reznitzky D, Gossen M, Bujard H, et al. Acceleration of the $\mathrm{G} / \mathrm{S}$ phase transition by expression of cyclins D1 and E

Paternelli P, Flejou JF, De Mitri MS, et al Structure and expression of the cyclin A gene in human primary liver expression of the cyclin A gene in human primary liver Hepatol 1995;23:47-52.

10 Motokura T, Arnold A. Cyclins and oncogenesis. Biochim Biophys Acta 1993;1155:63-78

11 Dutta A, Chandra R, Leiter LM, et al. Cyclins as markers of tumour proliferation: immunocytochemical studies in breast cancer. Proc Natl Acad Sci U S A 1995;92:5386-90.

12 Schadendorf D, Makki A, Stahr C, et al. Membrane transport proteins associated with drug resistance expressed in human melanoma. Am f Pathol 1995;147:1545-52.

13 Bales ES, Dietrich C, Bandyopadhyay D, et al. High levels of expression of $\mathrm{p} 27^{\mathrm{KIP} 1}$ and cyclin $\mathrm{E}$ in invasive primary malignant melanomas. F Invest Dermatol 1999;113:1039-46.

14 Keyomarsi K, Pardee AB. Redundant cyclin over-expression and gene amplification in breast cancer cells. Proc Natl Acad Sci U S A 1993;90:1112-16.

15 Keyomarsi K, O’Leary N, Molnar G, et al. Cyclin E, a potential prognostic marker for breast cancer. Cancer Res 1994;54:380-5

$16 \mathrm{Li}$ SF, Shiozawa T, Nakayama K, et al. Stepwise abnormalities of sex steroid hormone receptors, tumour suppressor gene products (p53 and $\mathrm{Rb}$ ), and cyclin $\mathrm{E}$ in uterine endometrioid carcinoma. American Cancer Society 1996;77:321-9.

17 Courjal F, Louason G, Speiser P, et al. Cyclin gene amplification and over-expression in breast and ovarian cancers. Evidence for the selection of cyclin D1 in breast and cyclin $\mathrm{E}$ in ovarian tumours. Int $\mathcal{F}$ Cancer 1996;69:247-53.

18 Wang A, Yoshimi N, Suzui M, et al. Different expression patterns of cyclins A, D1 and E in human colorectal cancer. $\mathcal{7}$ Cancer Res Clin Oncol 1996;122:122-6.

19 Lammie GA, Fantl V, Smith R, et al. D11S287, a putative oncogene on chromosome $11 \mathrm{q} 13$ is amplified and expressed in squamous cell and mammary carcinomas and linked to bcl-1. Oncogene 1991;6:439-44.

20 Zhang YJ, Jiang W, Chen JC, et al. Amplification and overexpression of cyclin D1 in human hepatocellular carcinoma. Biochem Biophys Res Commun 1993;196:1010-16.

21 Bartkova J, Lukas J, Strauss M, et al. Cyclin D1 oncoprotein Bartkova J, Lukas J, Strauss M, et al. Cyclin D1 oncoprotein
aberrantly accumulates in malignancies of diverse hisaberrantly accumulates in malign

22 Jiang W, Kahn SM, Tomita N, et al. Amplification and expression of the human cyclin D1 gene in oesophageal cancer. Cancer Res 1992;52:2980-3.

23 Callander T, El-Naggar A, Lee MS, et al. PRAD-1 (CCND1)/cyclin D1 oncogene amplification in primary head and neck squamous cell carcinoma. Cancer 1994;74: 152-8.

24 Leach FS, Elledge SJ, Sherr CJ, et al. Amplification of cyclin genes in colorectal carcinomas. Cancer Res 1993;53:1986-9.

5 Bringuier PP, Tamimi Y, Schuuring E, et al. Expression of cyclin D1 and EMS1 in bladder tumours; relationship with chromosome 11q13 amplification. Oncogene 1996;12: 1747-53.

26 Nikaido T, Li S, Shiozawa T, et al. Abnormal expression of cyclin D1 and p53 protein in human uterine endometrial carcinomas. American Cancer Society 1996;78:1248-53.

27 Volm M, Koomagi R, Stammler G, et al. Prognostic implications of cyclins (D1, E, A), cyclin-dependent kinases (cdk2, cdk4) and tumour-suppressor genes (pRb, $\mathrm{p} 16)$ in childhood acute lymphoblastic leukaemia. Int $\mathcal{f}$ Cancer 1997;74:508-12. 
28 Weinstat-Saslow D, Merino MJ, Manrow RE, et al. Over-expression of cyclin D1 mRNA distinguishes invasive and in situ breast carcinomas from non-malignant lesions. Nat Med 1995;12:1257-60.

29 Bartek J, Staskova Z, Draetta G, et al. Molecular pathology of the cell cycle in human cancer cells. Stem Cells 1993;1:51-8.

30 Malandsmo GM, Florenes VA, Hovig E, et al. Involvement of the $\mathrm{pRb} / \mathrm{p} 16 / \mathrm{cdk} 4 /$ cyclin D1 pathway in the tumorigenesis of sporadic malignant melanomas. $\mathrm{Br} \mathcal{F}$ Cancer 1996;73:909-16.

31 Inohara S, Kitagawa K, Kitano Y. Expression of cyclin D1 and $\mathrm{p} 53$ protein in various malignant skin tumors. Dermatology 1996;192:94-8.
32 Bosl GJ, Ilson DH, Rodriguez E, et al. Clinical relevance of I(12p) marker chromosome in germ cell tumours. $\mathcal{f}$ Natl Cancer Inst 1994;86:349-55.

33 Buckley MF, Sweeney KJ, Hamilton EA, et al. Expression and amplification of cyclin genes in human breast cancer. Oncogene 1993;8:2127-33.

34 Nakagawa H, Zuckerberg L, Togawa K, et al. Human cyclin D1 oncogene and oesophageal squamous cell carcinoma. Cancer 1995;76:541-9.

35 Tang L, Li G, Tron VA, et al. Expression of cell cycle regulators in human cutaneous malignant melanoma. Melanoma Res 1999;9:148-54. 